\title{
Anesthesia Management in Patient with Placenta Percreta Performed Intra-aortic Ballooning Caesarean Section
}

\author{
RTh. Supraptomo*, Alma Hepa Allan ${ }^{{ }^{*}}$
}

Article Info :

Submitted :

17-03-2021

Accepted

24-04-2021

Published

26-04-2021

https://doi.org/10.20961/soja.v

\section{$\underline{1 i 1.49481}$}

Authors' affiliations :

"Department of Anesthesiology and Intensive Therapy, Medical Faculty, Universitas Sebelas

Maret, Surakarta, Indonesia

${ }^{\square}$ Correspondence:

alma.anest@gmail.com

\begin{abstract}
Placenta accreta spectrum is one of maternal mortality's causes which is related with severe obstetric bleeding that requires hysterectomy. The incidence rate of the spectrum placenta increases with increasing caesarean section. Placenta accreta spectrum is also close-related to placenta previa. The aim of this study is to understand perioperative management in patient with placenta percreta performed with intra-aortic ballooning in caesarean section. We are following a case on a 36 year old female patient, multigravida at term pregnant with placenta percreta and history of caesarean section 5 and 2 years ago. The surgeries performed were caesarean section surgery as well as intra-aortic ballooning. Anesthetic technique used was general anesthesia. Operation duration approximately \pm 180 minutes, bleeding $1500 \mathrm{cc}$. After the operation, the patient was admitted to the ICU. The patient going well and discharged from ICU to ward on the second day. After three days in ward, the patient discharged to home. Hemodynamic changes during balloon intra-aortic procedures are of particular concern to anesthetists. This is because the stopping of blood flow to the aorta in this case can cause an increase in blood vessel pressure, where the administration of nitroglycerin at low doses can reduce venous tone resulting in venous vasodilation which will maintain hemodynamic stability during the process of blocking blood vessels with a balloon. From the case we may conclude that anesthesia in pregnant women with placenta accreta spectrum should be carried out with caution and involve a multidisciplinary specialist given its high risk of bleeding. The intra-aortic balloon insertion technique can be an option used to reduce the risk of bleeding in patients with placenta accreta spectrum.
\end{abstract}

Keywords: placenta accreta spectrum; general anesthesia; intra-aortic balloon 



\section{INTRODUCTION}

Placenta accreta is a condition in which implantation of the placenta occurs abnormally, including placenta increta, placenta percreta and placenta accreta. The cause of this condition is not fully understood, some experts hypothesize that the etiology of this spectrum is a defect in the endometriummyometrium that leads to failure of normal desidualization in the scar area of uterus, resulting in abnormal attachment by anchoring villi and infiltration of trophoblasts. ${ }^{1}$

The placenta accreta spectrum is considered a high-risk condition in pregnant women. This is due to the risk of bleeding that can arise during childbirth or during pregnancy. The risk of bleeding that appears can be life threatening to the mother and the fetus, so in many cases blood transfusions are required. Because of these reasons, patients on the placenta accreta spectrum were recommended for level 3 pregnancy care by the American College of Obstetricians and Gynecologists (ACOG) in 2015. ${ }^{1}$

The incidence of placenta accreta cases is more frequent than cases of placenta increta or percreta. In an analysis that included 138 cases with histological confirmation of abnormal placental implantation from the hysterectomy specimens, the percentage frequency and type were: placenta accreta $79 \%$, placenta increta $14 \%$, and placenta percreta $7 \%$. There were 1 in 731 cases of labor experiencing this condition, between 2008 and 2011 in the United States. ${ }^{3}$ The reported incidence of placenta accreta has increased to 3 per 1,000 deliveries over the past 10 years as caesarean section delivery increases. $^{4}$

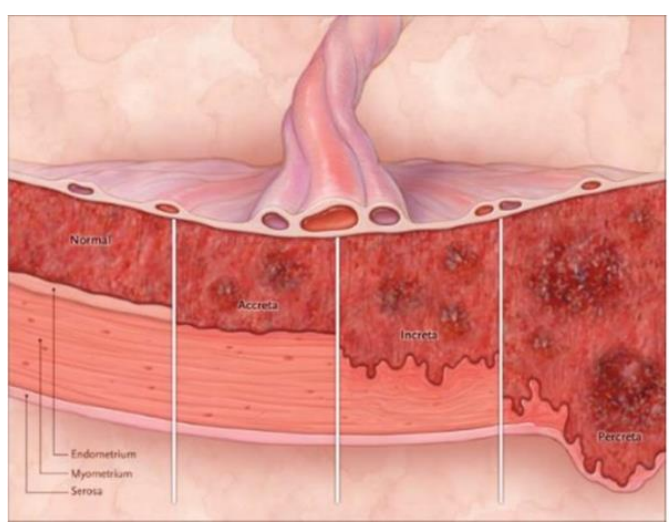

Figure. 1 The differences category in each placenta accreta spectrum.

Source: Silver RM, Branch DW. Placenta Accreta Spectrum. Solomon CG, editor. N Engl J Med [Internet]. 2018 Apr 19;378(16):1529-36. Available from:

http://www.nejm.org/doi/10.1056/NEJMcp1709324

The incidence of placenta accreta cases is more frequent than cases of placenta increta or percreta. In an analysis that included 138 cases with histological confirmation of abnormal placental implantation from the hysterectomy specimens, the percentage frequency and type were: placenta accreta $79 \%$, placenta increta $14 \%$, and placenta percreta $7 \%$. There were 1 in 731 cases of labor experiencing this condition, between 2008 and 2011 in the United States. ${ }^{3}$ The reported incidence of placenta accreta has 
increased to 3 per 1,000 deliveries over the increases. $^{4}$

Clinically, the placenta accreta spectrum becomes a problem during labor when the placenta is not completely detached from the uterus and is accompanied by massive bleeding which can lead to Disseminated Intravascular Coagulation, hysterectomy, damage to ureteral tissue, bladder, intestinal or neurovascular structures and kidney failure. Maternal mortality caused by placenta accreta is reported to be $20 \%$ and the average perinatal mortality is $30 \%$. Perreta placenta causes $7-10 \%$ of total maternal deaths in the world. ${ }^{3}$

The main modality in determining the antenatal diagnosis for placenta accreta spectrum cases is with the obstetric ultrasonography (USG). Ultrasound-visible placenta accreta may appear in the first trimester; however, most patients are diagnosed in the second and third trimesters. Patient with the risk factors of placenta accreta spectrum including placenta previa and evaluated by an obstetrician-gynecologist with the help of ultrasonography. ${ }^{1}$ In addition to ultrasound, some experts say MRI examinations can also be performed to make a diagnosis if necessary. ${ }^{4}$ past 10 years as caesarean section delivery previous caesarean delivery should be

The diagnosis of the placenta accreta spectrum during the antenatal period is crucial. It will be determining for better management and optimal results. The optimality of management are concerned with a standardized approach and multidisciplinary planning to minimize the potential for maternal morbidity and mortality. ${ }^{1-4}$

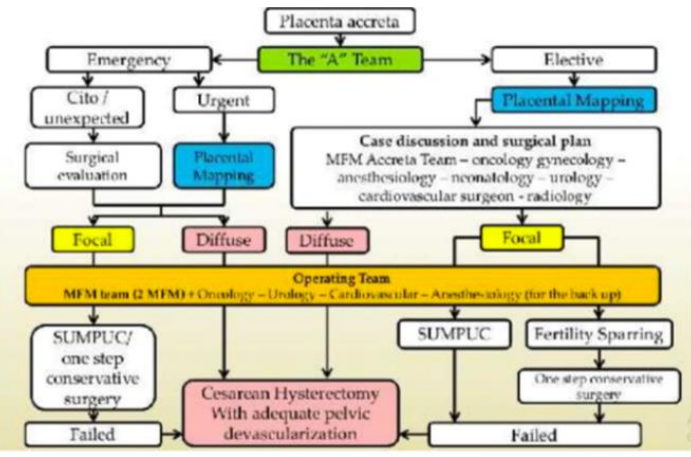

Figure 2. Placenta Accreta Spectrum Management

Cahill AG, Beigi R, Heine RP, Silver RM, Wax JR. Placenta Accreta Spectrum. Am J Obstet Gynecol [Internet]. 2018 Dec;219(6):B2-16. Available from: https://linkinghub.elsevier.com/retrieve/pii/S000293781 8308925

Elective caesarean delivery is recommended for such condition like placenta previa major and caesarean hysterectomy even though leaving the placenta in situ is recommended for placenta accreta. For patients with placenta accreta who still wish to maintain fertility, an alternative option is manual removal of the placenta by resection of the infected area and conservative management of leaving the placenta in situ; The former approach has possible risk of massive bleeding after placental separation, although the latter may be associated with 
secondary complications due to prolonged retention of the placenta. ${ }^{5}$

The duration of the surgical case and the estimate of blood loss are important considerations when determining the type of anesthesia. The American Society of Anesthesiologists Task Force on Obstetric Anesthesia recommends neuraxial anesthesia as the preferred initial approach. Most patients can tolerate prolonged surgery and significant blood loss with epidural anesthesia, with conversion to general anesthesia if clinically indicated. The conversion rate to general anesthesia is reported to be between $29 \%$ and $44 \%$. In the context of significant bleeding which requiring massive fluid resuscitation, endotracheal intubation and mechanical ventilation can be considered. ${ }^{6}$

Many elective caesarean sections for placenta accreta are performed under general anesthesia because of concerns about hemodynamic instability and the potential need for massive transfusions. However, in the classic caesarean hysterectomy study at five institutions from the 1980s, 32\% of planned caesarean hysterectomy was performed under regional anesthesia. There was no difference in intraoperative blood loss or hypotension, and none requiring induction of general anesthesia.

In the case of placenta accreta and increta, surgery to clamp the uterine blood supply after delivery is very effective in controlling blood loss. Many placenta accreta case series reports frequently document the need for a transfusion of four to six $\mathrm{pRBC}$ units. $^{7}$

Mean blood loss in cases of complicated placenta accreta spectrum ranged from 2000 to $5000 \mathrm{~mL}$ and in some studies more than $40 \%>5000 \mathrm{~mL}$. This catastrophic hemorrhage requires massive blood transfusions of various products. In one recent retrospective study assessing the need for transfusion of patients with placenta accreta spectrum, $95 \%$ of women received red blood cell transfusions and more than a third required more than 10 units. New retrospective review recently conducted at a high volume referral center showed that the percentage of patients receiving blood products was $71 \%$ (placenta accreta), 82\% (placenta increta) and $82 \%$ (placenta percreta). ${ }^{6}$

Intraoperative aortic balloon occlusion (IABO) has been shown to be effective at reducing intraoperative bleeding in major pelvic surgical procedures. In recent times, obstetricians have introduced this technique during caesarean section surgery in patients with placenta accreta and placenta previa because in addition to control the bleeding during hysterectomy, it also reduces the likelihood of hysterectomy. ${ }^{8}$

IABO may decrease the morbidity caused by placenta accreta spectrum cases 
because a more proximal occlusion can better address collateral circulation problems. The newer method of placing IABO under ultrasound guidance (USG guiding) eliminates the risk of fetal fluoroscopic exposure and allows placement in the same place so that all procedures can be performed without moving the patient. ${ }^{5}$

\section{CASE ILLUSTRATION}

\section{Patient History}

A woman aged 36 years with a body weight of $65 \mathrm{~kg}$ and height $155 \mathrm{~cm}$ present as G5P3A1 (multigravida) with a gestational age of 39 weeks came to the dr. Moewardi General Hospital with complaints of regular contractions was not yet in labor. Ultrasound examination is preformed. The results of USG examination showed that the placenta implantation in the lower uterine segment of the body extends to cover the internal uterine orificum with a MAP (Morbidly Adherent Placenta) score of 6 or moderate risk. Patients are planned to undergo elective caesarean section until hysterectomy. To reduce the risk of bleeding during surgery, the obstetrician and gynecologist in charge of the patient consulted the thoracic and cardiovascular surgeons for intra-aortic ballooning during the operation. The patient had a history of caesarean section surgery 2 times from previous deliveries in 2015 and 2018 under neuraxial anesthesia. The patient has no history of other comorbidities.

Table 1. Labolatory Examination Result (Preoperative)

\begin{tabular}{lll}
\hline Examination & Result & Unit \\
\hline $\mathrm{Hb}$ & $11.4^{*}$ & $\mathrm{~g} / \mathrm{dl}$ \\
$\mathrm{Ht}$ & 33 & $\%$ \\
$\mathrm{Al}$ & 10.09 & $/ \mathrm{mcl}$ \\
$\mathrm{At}$ & 155 & $/ \mathrm{mcl}$ \\
$\mathrm{Ae}$ & 3.79 & \\
Blood Type & $\mathrm{A}$ & \\
$\mathrm{PT}$ & 12 & $\mathrm{secs}$ \\
APTT & 31 & $\mathrm{secs}$ \\
INR & 0.86 & \\
Blood & 83 & $\mathrm{mg} / \mathrm{dl}$ \\
Glucose & & \\
Level & & \\
SGOT & 15 & \\
SGPT & 8 & \\
Albumin & 3.9 & $\mathrm{~g} / \mathrm{dl}$ \\
Cr & 0.7 & $\mathrm{mg} / \mathrm{dl}$ \\
Ur & 18 & $\mathrm{mg} / \mathrm{dl}$ \\
Na & 136 & $\mathrm{mmol} / \mathrm{l}$ \\
K & 3.9 & $\mathrm{mmol} / \mathrm{l}$ \\
Cal & 1.23 & $\mathrm{mmol} / \mathrm{l}$ \\
Hbsag & Non & \\
& Reactive & \\
\hline
\end{tabular}

Physical Examinations

The patient is in a conscious state with Glasgow Comma Scale E4V5M6 and the vital sign such as; blood pressure 120/77 $\mathrm{mmHg}$, pulse rate $76 \mathrm{x} /$ minute, regular and strong, respiratory rate $18 \mathrm{x} /$ minute. Pulmonary examination within normal limits. Warm, red, and CRT <2 seconds. Fetal heart rate $138 \mathrm{bpm}$. Spontaneous production of clear colored urine. Routine hematological data (Table 1.) revealed mild anemia. Ultrasound examination of the uterus shows 
the insertion of placenta in the lower uterine segment to cover the internal uterine orifice.

Anesthetic Management

Patients with ASA 2 of physical status. The plan of caesarean section to hysterectomy with general anesthesia rapid sequence induction. Patients and families are educated to undergo surgery under general anesthesia and high-risk surgery with profuse bleeding. The patient was provided with 2 intravenous access lines with iv cath no 18 . The patient was fasted and given premedication with metoclopramide $10 \mathrm{mg}$ and ranitidine 50mg iv. Blood products were prepared 4 units of PRC, 4 units of FFP and 4 units of TC. When the patient arrived in the operating room, the patient's anesthesia team carried out the installation of invasive monitoring of the arterial line and central venous catheter under local anesthesia before the anesthesia was carried out. The vascular surgery team performed an angioplasty balloon cateter in the right femoral artery under local anesthesia. The operation was started when all patient monitoring preparations had been put in place, where the initial vital signs were blood pressure 121/71 $\mathrm{mmHg}$, pulse rate $84 \mathrm{bpm}$, breath rate 22 $\mathrm{x} /$ minute. The patient is positioned supine on the operating table, the operator is asked to prepare the operating field first, then induction is done using fentanyl $100 \mathrm{mcg}$, propofol $80 \mathrm{mg}$ and rocuronium $50 \mathrm{mg}$ iv, then the patient is intubated using ETT no 7.0 with a depth of 20, maintenance of anesthesia with $\mathrm{N} 2 \mathrm{O}$ in $50 \%$ oxygen and sevoflurane up to $1-2$ vol\%.

The patient is wearing a warmer blanket to prevent hypothermia. On the operating field, vascularization was seen in the lower uterine segment visible on the outer wall of the uterus and it was decided to do the caesarean procedure and hysterectomy. An incision is made in the uterine fundus and after birth the fetus is given 10iu of oxytocin drip, after which the placenta remains in the uterus and a situational uterine suture is performed while still controlling the source of bleeding. Prior to the hysterectomy, the vascular surgical team placed intra-aortic ballooning through the femoral artery with the target of balloon expansion or blockade of the distal abdominal aorta to prevent perfusion of blood into the uterus from the uterine artery, guided by the C-arm during balloon insertion. After arriving at the target location, the balloon lumen was inflated by $10 \mathrm{cc}$, monitoring the success of the blockade was carried out by assessing the saturation of the patient's legs where $0 \%$ saturation was obtained in both legs and the obsgyn team continued the hysterectomy for approximately 45 minutes. Ballooning process can cause hemodynamic instability 
such as hypertension in the proximal area of the balloon and hypotension in the distal area of the balloon. Therefore, the patient was given an NTG syringe pump of 0.25 $\mathrm{mcg} / \mathrm{kg} / \mathrm{min}$ from the time the intra-aortic ballooning was placed until the hysterectomy was completed to reduce blood pressure and aortic spasm due to ballooning. Ballooning begins to reduce its development after the hysterectomy is completed with the removal of the uterus, the pressure reduction is carried out gradually while still evaluating and controlling the source of bleeding so that if there is still bleeding, ballooning can be developed again. During the process of the returning of iliac artery flow so the NTG syringe pump was turned off and the patient was given an $\mathrm{N}$-epi syringe pump at a dose of $0.1 \mathrm{mcg} / \mathrm{kg} / \mathrm{min}$. After the onset of N-epi is achieved, the pressure on the balloon is reduced until it is finally released.

During the operation, the bleeding was about $1500 \mathrm{cc}$ with liquid entering Ringer's lactate $2500 \mathrm{cc}, \mathrm{NaCl} 0.9 \% 500 \mathrm{ml}$, gelofucin $1000 \mathrm{cc}$ and transfusion of 1 unit of PRC. Urine production was 700cc in 3 hours and operating stress of $900 \mathrm{ml}$ fluid maintenance for 3 hours. The intraoperative hemodynamic status (Figure 1) tended to be stable with systolic blood pressure in the range of $110-130 \mathrm{mmHg}$, diastolic $70-$
$90 \mathrm{mmHg}$, heart rate $70-90 \mathrm{x} / \mathrm{m}$ and observed $\mathrm{SpO} 2$ of $99-100 \%$.

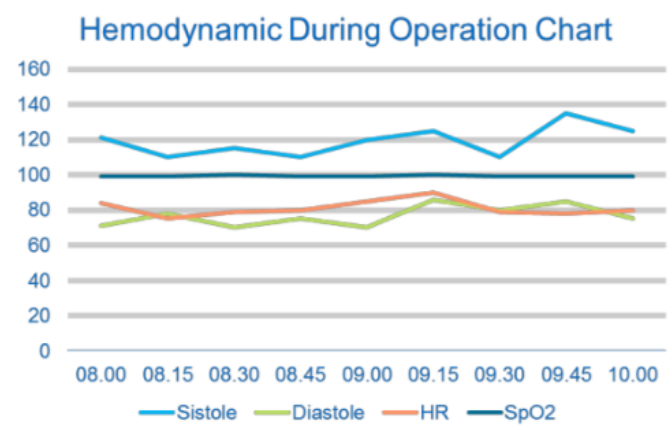

Figure 3.Patient's Hemodynamic Chart

\section{Post Operation Management}

At the end of the operation, the patient was not extubated and was admitted to the ICU, considering the presence of bleeding during surgery and the risk of recurrent bleeding, so that requires close monitoring in the intensive room. Management of postpartum pain was given paracetamol $1 \mathrm{~g}$ every 8 hours and fentanyl syringe pump at a dose of $0.5 \mathrm{mcg} / \mathrm{kg} / \mathrm{hour}$,postoperative laboratory results (Table 2.) shows that hypocalcemia was corrected by giving $\mathrm{Ca}$ Gluconas 1 extra ampoule and hypomagnesemia was corrected by administering $\mathrm{MgSO} 42$ grams are depleted in 1 hour. During the ICU treatment, the obsgyn team monitored the bleeding signs from the postoperative site and the vascular surgery team checked the vascular status starting from a. femoral, a. poplitea, a. tibialis, and a. dorsalis pedis, obtained strong pulse results and good perfusion. The patient 
was extubated 24 hours postoperatively and the patient could be transferred to the inpatient ward on the second day of postoperative day and the patient could be discharged on the fifth day of post-operative day.

Table 2. Laboratory Examination Result (Postoperative)

\begin{tabular}{lll}
\hline Examination & Result & Unit \\
\hline $\mathrm{Hb}$ & $9.9^{*}$ & $\mathrm{~g} / \mathrm{dl}$ \\
$\mathrm{Ht}$ & $28^{*}$ & $\%$ \\
$\mathrm{Al}$ & $14.9^{*}$ & $/ \mathrm{mcl}$ \\
$\mathrm{At}$ & 154 & $/ \mathrm{mcl}$ \\
$\mathrm{Ae}$ & 3.2 & \\
$\mathrm{Albumin}$ & $3.0^{*}$ & $\mathrm{~g} / \mathrm{dl}$ \\
$\mathrm{Na}$ & 134 & $\mathrm{mmol} / \mathrm{l}$ \\
$\mathrm{K}$ & 3.6 & $\mathrm{mmol} / \mathrm{l}$ \\
$\mathrm{Cal}$ & $0.8^{*}$ & $\mathrm{mmol} / \mathrm{l}$ \\
$\mathrm{Mg}$ & 0.36 & $\mathrm{mg} / \mathrm{dl}$ \\
$\mathrm{Cr}$ & $0.5^{*}$ & $\mathrm{mg} / \mathrm{dl}$ \\
$\mathrm{Ur}$ & 21 & $\mathrm{mg} / \mathrm{dl}$ \\
\hline
\end{tabular}

\section{DISCUSSION}

Evaluation and pre-anesthesia planning for antenatal patients who are considered to be at high risk of bleeding are essential to achieve optimal postoperative outcomes. The role of the anesthesiologist ideally begins long before the patient arrives at the delivery room. An outpatient antepartum, pre-anesthetic consultation as an outpatient is an important step in preparing and drawing up a plan for women who are considered to be at high risk of bleeding during labor. It is important to collaborate with an obstetrician to evaluate suspected Morbidly Adherent Placenta based on several criteria in (Table 3.)

Table 3. Morbidly Adherent Placenta (MAP) Criteria

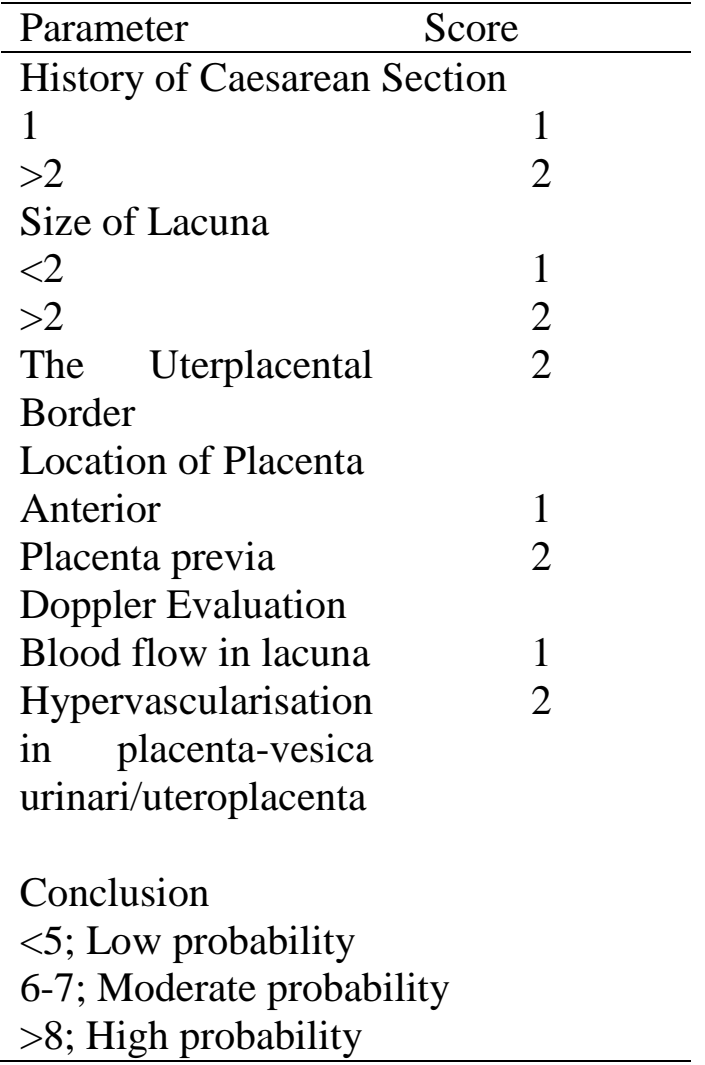

Preoperative optimization is very important in minimizing the problems that may arise in high-risk pregnant women. Family education on all the risks associated with surgery and anesthesia during surgery is an important thing that should not be missed, the necessary intravenous access during the operation, invasive monitoring, emergency medications must be readily available until the availability of blood is carefully prepared. Selection of the type of anesthesia in this case can use general or regional anesthesia, 
however most anesthesiologist prefer general anesthesia considering the large risk of bleeding that can occur in patients with moderate or high risk MAP. Other advantages of general anesthesia are controlled ventilation and more stable hemodynamic monitoring during the course of surgery. Complications that can occur in patients with placenta accreta besides bleeding are other complications such as disseminated intravascular coagulation (DIC), complications from massive transfusions, acute respiratory distress syndrome and trauma to the abdominal organs during labor and removal of the uterus.

Previous caesarean section surgery history can increase the incidence of placenta accreta and coupled with the placenta blocking the birth canal from the results of ultrasound examination were putting the patient at high risk of bleeding. Bleeding that occurs in a patient with placenta percreta in this case is a major concern for the anesthetist during the operation. Invasive monitoring preparations are used for actual hemodynamic monitoring, placement of a central venous catheter for resuscitation if necessary, blood availability prior to surgery and supportive drugs such as vasopressors and vasodilators. In this case, the preparation for prevention of bleeding is not only a role for the anesthetist but also the role of other operators. In this case the gynecologist consults a vascular surgeon to perform intraaortic ballon insertion to reduce the risk of bleeding during surgery. This procedure can minimize bleeding by reducing the perfusion of blood to the uterus during the uterine removal procedure in this case.

Installation of an intra-aortic balloon will be decreasing the regional perfusion and limiting bleeding in labor in the presence of abnormal adhesions as in this case. The most commonly performed vascular blockade is the internal iliac artery, which in this case targets the blockade of intra-aortic ballon placement in the distal abdominal aorta or before the abdominal aorta branches into the right and left common iliac arteries. Important things that need to be considered in this procedure are the potential risk of ischemic in the lower extremities, aortic rupture, the potential for embolization of the plaque from the distal blood vessels and to the difficulty in loosening and removing the balloon from the catheter. Therefore, it is necessary to pay attention to the time limit of balloon installation. Several studies have recommended a safe time limit for this surgical technique to be 45-60 minutes, where the highest risk is lower limb ischemia. Recent studies have recommended for the balloon development of vascular 
occlusion after being maintained for no more than 40 minutes which the balloon is deflated for approximately 10 minutes to prevent limb ischemia.

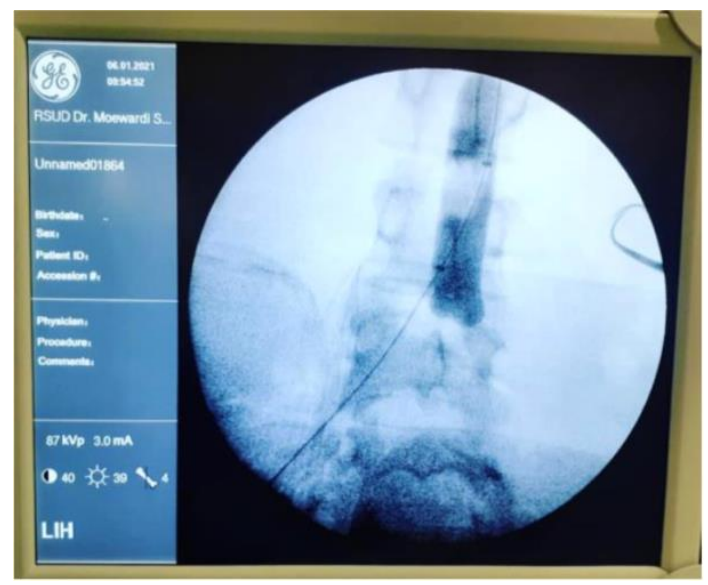

Figure 4. Insertion of Intra-aortic Ballooning with C-Arm Guidance

Hemodynamic changes during balloon intra-aortic procedures are of particular concern to anesthetists. This is because the stopping of blood flow to the aorta in this case can cause an increase in blood vessel pressure, where the administration of nitroglycerin at low doses can reduce venous tone resulting in venous vasodilation which will maintain hemodynamic stability during the process of blocking blood vessels with a balloon. The anesthesiologist also needs to pay attention to the process of releasing the balloon, where the blood flow that was previously blocked will return to the lower extremities. So that the balloon deflation process is not too fast and the balloon deflation process is carried out in stages accompanied by hemodynamic monitoring of the patient. To maintain the stability of the backflow, vasoconstrictor drugs can also be given to increase systemic vascular resistance.

\section{CONSLUSION}

Intra-aortic balloon insertion technique can be an option used to reduce the risk of bleeding in patients with placenta accreta. Anesthetic management of patients with the risk of bleeding from the start is very important step in order to avoid unexpected complications. Preparation of patients for a higher facility (ICU), as well as monitoring of postpartum pain, can improve postoperative recovery.

\section{REFERENCE}

1. Cahill AG, Beigi R, Heine RP, Silver RM, Wax JR. Placenta Accreta Spectrum. Am J Obstet Gynecol [Internet]. 2018 Dec;219(6):B2-16. Available from: https://linkinghub.elsevier.com/retrieve /pii/S0002937818308925

2. Silver RM, Branch DW. Placenta Accreta Spectrum. Solomon CG, editor. N Engl J Med [Internet]. 2018 Apr 19;378(16):1529-36. Available from:

http://www.nejm.org/doi/10.1056/NEJ 
Mcp1709324

3. Rajuddin R, Roziana R, Munawar M, Iqbal M. Management Placenta Percreta Succesfully With Total Abdominal Hysterectomy. A Case Review: AVERROUS J Kedokt dan Kesehat Malikussaleh [Internet]. 2019 Jul 25 [cited 2021 Mar 8];5(1):52. Available from: https://ojs.unimal.ac.id/index.php/averr ous/article/view/1628

4. Purwoko R, Rusman M, Ridho A. Serial Kasus: Manajemen Anestesi pada Wanita Hamil dengan Plasenta Akreta yang Direncanakan Tindakan Seksio Sesarea [Internet]. Vol. 3, Jurnal Anestesi Obstetri Indonesia. 2020 [cited 2021 Mar 8]. p. 26-34. Available from:

https://jurnalanestesiobstetri-

indonesia.id/ojs/index.php/Obstetri/arti cle/view/40

5. Blumenthal E, Rao R, Murphy A, Gornbein J, Hong R, Moriarty J, et al. Pilot Study of Intra-Aortic Balloon Occlusion to Limit Morbidity in Patients with Adherent Placentation
Undergoing Caesarean Hysterectomy. Am J Perinatol Reports [Internet]. 2018 Apr 11;08(02):e57-63. Available from: http://www.thieme-

connect.de/DOI/DOI?10.1055/s-00381641736

6. Silver RM. Abnormal Placentation. Obstet Gynecol [Internet]. 2015 Sep;126(3):654-68. Available from: https://journals.lww.com/00006250201509000-00030

7. Reitman E, Devine PC, Laifer-Narin SL, Flood P. Case Scenario. Anesthesiology [Internet]. 2011 Oct;115(4):852-7. Available from: http://anesthesiology.pubs.asahq.org/art icle. asp $x$ volume $=115 \&$ page $=852$

8. Luo F, Xie L, Xie P, Liu S, Zhu Y. Intraoperative aortic balloon occlusion in patients with placenta previa and/or placenta accreta: a retrospective study. Taiwan J Obstet Gynecol [Internet]. 2017 Apr 1 [cited 2021 Mar 8];56(2):147-52. Available from: https://pubmed.ncbi.nlm.nih.gov/28420 4 